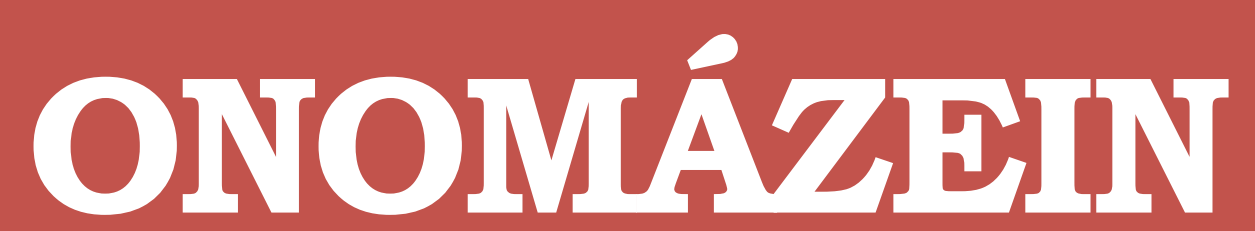

Revista de lingüística, filología y traducción
PONTIFICIA UNIVERSIDAD CATÓLICA DE CHILE FACUITAD DE LETRAS

\title{
Viaje o turismo a finales del siglo XIX y principios del XX
}

Travel or tourism in the late nineteenth

and early twentieth centuries

Número especial

- VII -

Discurso

turistico,

lenguas y

traducción

2020

\section{Julia Pinilla Martinez}

Universidad de Valencia

ONOMÁZEIN | Número especial VII - Discurso turístico, lenguas y traducción: 175-190

DOI: 10.7764/onomazein.ne7.12

ISSN: 0718-5758

\section{(c) $($ ii $\ominus$}

Julia Pinilla Martinez : Departamento de Filología Francesa e Italiana. Universidad de Valencia. ORCID: 0000-0001-9871-5028 | E-mail: julia.pinilla@uv.es 


\section{Resumen}

Los relatos de los viajeros franceses del siglo xIx a España y su visión exótica del país son bien conocidos. Muchos fueron los que dejaron plasmadas sus impresiones sobre el país, desde autores tan populares como Georges Sand y su obra Un hiver à Majorque (1855), traducida en 1902, hasta la ginebrina Valérie de Gasparin. En 1869, se publicó en París una de sus obras À travers les Espagnes, cuya versión en español se tituló Paseo por España (Valencia, 1875). La traducción de esta obra constituye el punto de partida de nuestro artículo, pues enlaza directamente con la prensa como vehículo de información "turística” sobre las diferentes ciudades de España. En este trabajo expondremos la relevancia de los libros de viajes, la prensa e incluso los libros de arquitectura como Espagne, Portugal. Notes historiques et artistiques sur les villes principales de la Péninsule ibérique, del arquitecto francés Gustave Clausse (París, 1889), en la evolución paulatina del viaje al turismo.

Palabras clave: traducción; relatos de viaje; prensa; turismo.

\section{Abstract}

The stories of 19th century French travellers to Spain and their exotic vision of the country are well known. Many left their impressions of the country, from populars authors such as Georges Sand and his work Un hiver à Majorque (1855), translated in 1902, to the Geneva-based Valérie de Gasparin. In 1869, one of his works À travers les Espagnes, was published in Paris, the Spanish version of which was entitled Paseo por España (Valencia, 1875). The translation of this work is the starting point of our article as it links directly to the press as a vehicle for "tourist" information on the different cities of Spain. In this work we will expose the relevance of travel books, the press and even architecture books such as Espagne, Portugal. Notes historiques et artistiques sur les villes principales de la Péninsule ibérique, by French architect Gustave Clausse (Paris, 1889), in the gradual evolution of travel to tourism.

Keywords: translation; travel stories; press; tourism. 


\section{Introducción}

El siglo xIX es el exponente máximo de la curiosidad por descubrir lo desconocido —pensemos en los exploradores - pero también lo diferente, lo exótico. España representó para algunos escritores franceses ese exotismo que sería ampliamente difundido a través de los relatos de viaje, ya clásicos, de autores como Théophile Gautier (1811-1872) en Voyage en Espagne (París, 1843) o Georges Sand y su obra Un hiver à Majorque (1855), traducida en 1902, creando en muchos casos unos tópicos difíciles de erradicar. Naturalmente, no todos los que escribieron sobre España fueron franceses, también lo hicieron autores alemanes e ingleses. En efecto, la voz turismo o tourisme procede del término inglés tourism y tiene su origen en los viajes que los jóvenes aristócratas ingleses hacían por Europa para completar su formación Ilamados Gran tour. No obstante, en este artículo nos limitaremos a los autores francófonos.

Entre los autores estudiados se ha concedido un lugar destacado a las viajeras. En la segunda mitad del Ochocientos la literatura escrita por mujeres deja de ser minoritaria. Su situación social va cambiando: viajan solas, se atreven a explorar mundos desconocidos, sobre todo Oriente. Una actividad hasta entonces reservada a los hombres. Además, estas viajeras recogen sus experiencias en obras que serán publicadas más tarde. En algunos casos, será la prensa la encargada de llevar a cabo dichas publicaciones. Por esta razón, hemos considerado oportuno dedicar un apartado a este medio que, como es sabido, tiene su eclosión en el siglo XIX y desempeñó un papel relevante en su función divulgadora en general y de la literatura de viajes en particular.

Hemos estructurado nuestro trabajo en cuatro apartados, el primero y más vasto dedicado a las mujeres viajeras por lo anteriormente expuesto. El segundo tiene como objeto la prensa por su función en la difusión de los relatos de los escritores en general y en nuestro análisis, en particular, por la publicación de la traducción de la obra de una de las autoras consideradas. Para completar el estudio, hemos creído conveniente describir un tipo de viajero hombre en este caso- con una sólida formación técnica o científica que hubiese escrito sus impresiones sobre España desde otro punto de vista. Todo ello con el fin de constatar la evolución de los relatos. Finalmente, en el último apartado recogemos dos textos ejemplo de guías de viajes contemporáneos de los relatos.

\section{Viajeras por España}

\subsection{Joséphine de Brinkmann}

No todos los viajeros que nos visitaron y plasmaron sus experiencias fueron escritores tan conocidos y reconocidos, ni todos hombres. Francisco Lafarga (2017: 251) ofrece una lista de once viajeras que visitaron nuestro país cuyas obras fueron publicadas en la segunda mitad del siglo XIX. Joséphine de Brinkmann, cuyo apellido de soltera era Dupont-Delporte (¿1808?), 
publicó en 1852 un relato de viajes sobre España titulado Promenades en Espagne pendant les années 1849 et 1850. Redactado en forma epistolar, las cartas se dirigen a su hermano Hugues Delporte; en ellas describe el paisaje, los monumentos, el carácter de los españoles distinto según las regiones y sus costumbres. Considera que este viaje y su libro serán de utilidad a los turistas. Vemos en su primera carta, redactada a modo de introducción, que su obra no es un simple relato de viajes pensado para entretener, sino una guía, pues "espera ofrecer a los turistas informaciones útiles". Sorprende su punto de vista, claramente femenino, y su clasificación del turista.

Por un lado, el no turista, es decir, aquel que, imbuido por las lecturas de relatos de viajes inexactos o fantasiosos, se aburre al no encontrar lo que busca y regresa enfadado a su país.

Como solo conoce de España lo que ha leído en la preciosa poesía de Victor Hugo o Alfred de Musset, cree poder alegrar su triste vida y olvidar sus problemas cerca de alguna andaluza de tez morena [...]. Este turista es el que ha contribuido a propagar una reputación nefasta de España; reputación que se ha afianzado a pesar de este homme-borne a quien niego la calificación de turista‥ (Brinkmann, 1852: 4)

Por otro lado, el que considera verdadero turista:

La segunda especie es, como acabo de decir, el hombre que quiere alimentar su inteligencia, deseoso de comprender cualquier cosa; que siente una atracción infinita por la observación y el estudio, en la contemplación de la hermosa naturaleza bajo un cielo encantador, en la de los grandes y nobles vestigios que permanecen como testimonio de los días de esplendor de la vida de las naciones. A estos les diría: id a España, encontraréis todo cuanto puede alimentar el espíritu y conmover el corazón². (Brinkmann, 1852: 4)

No cabe duda de que Joséphine Brinkmann es una viajera deseosa de descubrir la belleza de los lugares que visita y ampliar sus conocimientos. Desde nuestra óptica del siglo XxI difícilmente podríamos considerarla turista debido a su interés intelectual por todo lo que la rodea.

$1 \quad$ La traducción es nuestra. Texto origen: “Comme il ne sait de l'Espagne que ce qu'il a lu dans les poésies charmantes de Victor Hugo ou d'Alfred de Musset, il croit pouvoir retremper sa pâle vie et dissiper ses ennuis près de quelque Andalouse au teint bruni [...]. C'est donc ce touriste-là qui a contribué à faire à l'Espagne une fâcheuse réputation; réputation qui s'est accréditée, malgré l'absurde exagération de cet homme-borne auquel je refuse la qualification de touriste" (Brinkmann, 1852: 4).

2 La traducción es nuestra. Texto origen: "La deuxième espèce est, comme je viens de le dire, l'homme qui veut alimenter son intelligence, augmenter la masse de son intelligence en toute chose; qui trouve un charme infini dans l'observation et l'étude, dans la contemplation d'une belle nature sous un ciel enchanteur, dans celle des grands et nobles restes qui sont là comme témoignagnes des beaux jours de la vie des nations. À ceux-là, je dirai : Allez en Espagne, vous y trouverez tout ce qui peut charmer l'esprit, comme tout ce qui peut toucher le coeur" (Brinkmann, 1852: 4). 
Otro de los elementos reseñables de esta obra es su traducción tardía (2001) por María Luisa Burguera Nadal publicada en la editorial Cátedra con el título Paseos por España.

\subsection{Juliette de Robersart (1824-1900)}

La segunda de las viajeras que nos visitaron en el siglo xix es la condesa belga Juliette de Robersart (1824-1900), cuyo viaje quedó plasmado en sus Lettres d'Espagne par la comtesse J. de Robersart. Su obra tuvo dos ediciones, aunque únicamente se conserva la segunda Nouvelle édition considérablement augmentée (1879), a decir de la estudiosa de la literatura belga Estrella de la Torre Giménez. El estilo de la condesa difiere totalmente de Joséphine Brinkmann excepto en la macroestructura de la obra, concebida igualmente de forma epistolar. Se trata de un conjunto de cartas dirigidas en su mayor parte a su íntima amiga Charlotte de Gramont ${ }^{3}$ en las que plasma los sentimientos que le producen los lugares que visita, principalmente los religiosos, comparando a menudo las costumbres belgas con las españolas.

Ayer por la mañana fui al famoso hospicio de la Caridad; me habían dicho que encontraría a las monjas de San Vicente de Paúl, lo que me producía una gran alegría. [...] El hospital, magnífico, está extremadamente limpio como si fuera belga; las salas están oreadas y los enfermos huelen a rosas.

La iglesia posee el Moisés de Murillo, la gran obra de arte tan alabada; es divino. Tiene asimismo otros cuadros de renombre en Europa, entre otros un Valdés representando el cadáver de un arzobispo [...]. Como nosotros, los españoles son orgullosos y de pocas palabras [...]. Bélgica y Andalucía se parecen mucho. Aquí somos muy apreciados y nos llaman flamencos. Muchos españoles tienen algo de nuestra sangre en las venas y descienden de la famosa Guardia Valona ${ }^{4}$. (Robersart, 1879: 44-45)

Se percibe en la cita anterior el gran interés de la viajera por visitar los lugares píos como el hospicio y hospital de la Caridad. Según el artículo publicado en El correo de Andalucía con fecha 22 de agosto de 2020, "[e]I hospicio existió durante ocho años, tras los cuales la Hermandad [de la Caridad] tomó la decisión de ampliarlo y convertirlo en hospital”. Sevilla

3 Para mayor información sobre la obra de Robersart, véase Estrella de la Torre Giménez (2006).

4 La traducción es nuestra. Texto origen: "Je suis allée hier matin au célèbre hospice de la Caridad; on m'avait dit que j’y trouverais des soeurs de Saint Vincent de Paul et je m'en réjouissais. [...] L'hôpital, qui est magnifique est tenu avec l'extrème propreté de la Belgique; les salles sont aérées et les malades sentent la rose.

L'église possède le Moïse de Murillo, le chef-d'oeuvre vanté ; c'est divin. Elle a encore d'autre tableaux d'une renommée européenne, entre autre un Valdès, représentant le cadavre d'un archevêque [...]. Comme nous, les Espagnols sont fiers et de peu de paroles [...] la Belgique et l'Andalousie ont une grande ressemblance. Nous sommes très aimés-ici (sic) et on nous appelle Flamingos. Beaucoup d'Espagnols ont de notre sang dans les veines et descendent des fameuses gardes wallones" (Robersart, 1879: 44-45) 
le produce una gran emoción que se plasma en la descripción de la catedral, parte de la cual transcribimos a continuación.

Los órganos gigantescos tienen innumerables tubos. Hay ochenta y tres vidrieras; las más bellas y antiguas fueron pintadas por Arnold de Flandes. Las capillas tienen cada una sus propias obras maestras. La iglesia está llena de esculturas en piedra, madera, plata, de Juan de Arfe, Juan Millán, Roldán, Montañés; pinturas de Murillo, Zurbarán, Pedro de Campaña, Roëlas, Don Luiz de Villegas, Herrera el Viejo y el Joven, Juan Valdés, Goya5. (Robersart, 1879: 47)

Su mirada religiosa impregna todo el relato, así como su satisfacción por todo lo que permanece inmutable a pesar de los cambios sucedidos en Europa desde finales del siglo XVIII. Observamos que nuestra segunda autora, Juliette de Robersart, tampoco fue una turista, sino una viajera culta que aborrecía las alteraciones de los usos del pasado y con ello la destrucción de las obras. Su libro no puede considerarse, a nuestro parecer, un relato turístico a pesar de la minuciosidad con que detalla todo lo realmente valioso en su opinión. Al tratarse de su segundo viaje a España, apenas se detiene en las difíciles condiciones de los transportes españoles, como era usual en los relatos de viaje, si bien es cierto que en esas fechas el ferrocarril aligeraba el viaje.

\subsection{Jane Dieulafoy (1851-1916)}

Dentro de los relatos de viajeras, hemos incluido dos de Jane Dieulafoy (1851-1916), cuyo nombre de soltera era Jeanne Henriette Magre, a saber, Aragon et Valence (1901) y Castilla et Andalousie (1908). Esta autora presenta unas características totalmente distintas a las dos anteriores. Dieulafoy fue una mujer singular. Al casarse con Marcel Dieulafoy a los 19 años se convirtió en su compañera inseparable. Su esposo, arqueólogo y arquitecto como ella, dedicó su vida a distintos proyectos arqueológicos en Oriente - uno de ellos en Persia-, así como en España. Jane estuvo siempre a su lado, primero combatiendo en la guerra franco-prusiana (1870-1871), más tarde como su compañera en los trabajos arqueológicos Ilevados a cabo en Oriente y sus viajes a España. Fue singular asimismo por su decisión de ir siempre vestida de hombre. A decir de Shojaeddin Shafa (Huelva, 2000), traducido por M. Ángeles Gallego García,

Marcel Dieulafoy y su esposa Jane Dieulafoy, (sic) — dos nombres indisociables - consagraron casi cincuenta años de su vida y hasta poco antes de su muerte, a la arquitectura y arqueología de Irán y España [...]. De 1897 a 1908, esta pareja de arquitectos y arqueólogos se dedicó a investigaciones

5 La traducción es nuestra. Texto origen: "Les orgues gigantesques ont d’innombrables tuyaux. On compte quatre-vingt-trois vitraux ; les plus beaux et les plus anciens ont été peints par Arnold de Flandre. Les chapelles ont chacune leurs chefs-d'oeuvre. L'église est remplie de sculptures en pierre, en bois, en argent, de Juan d'Arfé, de Juan Millan, de Roldan, de Montañes; des peintures de Murillo, de Zurbaran, de Pierre Campaña, de Roëlas, de Don Luiz de Villegas, des Herrera vieux et jeune, de Juan Valdès, de Goya" (Robersart, 1879: 47). 
[...] en la Península Ibérica, a donde realizaron veintitrés viajes, recorriendo la Península en todos los sentidos, para intentar conocer lo mejor posible su arte y su literatura. (Shafa, 2000: 77)

Su faceta como arqueóloga es sobradamente reconocida, entre otros méritos, por la colección de piezas que trasladó a París y que se exponen en el museo del Louvre, quien en agradecimiento a esta aportación le dedicó una sala. Pero lo que nos interesa en este artículo es su dimensión como escritora, periodista y fotógrafa. Escribió principalmente sobre los viajes que realizó y obras históricas 6 . Sus primeros textos de viajes se publicaron en 1883 en la revista Le tour du monde. Nouveau journal des voyages en el número xLv con el título "La Perse, la Caldée et la Susiane par Mme Jane Dieulafoy, officier d’Académie”. En ella publicó asimismo en 1900 su relato Aragon et Valence, que vería la luz en formato libro al año siguiente.

En Aragon et Valence, la autora concede gran importancia al relato histórico del país como forjador del carácter de los españoles; así lo expresa en el prólogo:

Pero aunque España se formó de provincias cristianas, creció demasiado cerca de los reinos musulmanes como para no haber sido influenciada por estos. Veremos más tarde cuán profunda y duradera fue esta influencia en el alma, corazón, espíritu e inteligencia de esta nación heroica. No en vano sufre un país una dominación de ocho siglos?. (Dieulafoy, 1901: prólogo sin paginar)

No creo necesario insistir, pues ya se ha escrito mucho al respecto, en la atracción que suponía para los viajeros del siglo xıx el orientalismo del país.

La variedad orográfica también representa un factor sustancial:

Generalmente, existen en cada provincia montañas más o menos altas que las separan del conjunto del reino como lo está la Península Ibérica del resto de Europa. Debido a ello, el clima, la flora, la raza muestran modificaciones profundas según la latitud, altitud y orientación. Estos caracteres singulares y las dificultades para comunicarse facilitaron la constitución de grupos autónomos harto distintos ${ }^{8}$. (Dieulafoy, 1901: prólogo sin paginar)

6 Información extraída del catálogo de la Bibliothèque Nationale de France (en línea).

7 La traducción es nuestra. Texto origen: “Mais si l'Espagne s'est faite de provinces chrétiennes, elle a grandi trop près des royaumes musulmans pour ne pas en avoir subi l'influence. On verra par la suite combien elle fut profonde et durable sur l'âme, le coeur, l'esprit et l'intelligence de cette heroïque nation. Ce n'est pas en vain qu'un pays subit une domination de huit siècle" (Dieulafoy, 1901: prólogo sin paginar).

8 La traducción es nuestra. Texto origen: “D’une manière générale, il existe dans chaque province des chaines de montagne plus ou moins hautes qui les séparent de l'ensemble du royaume comme la Péninsule Ibérique l'est du reste de l'Europe. II en résulte que le climat, la flore, la race subissent des modificactions profondes en rapport avec les différences de latitude, d'altitude et d'orientation. Ces caractères particuliers les difficultés de communication facilitèrent la constitution de groupes autonomes bien distincts" (Dieulafoy, 1901: prólogo sin paginar). 
A continuación, describe las peculiaridades de los habitantes de cada región, que justifica por las características descritas en las citas anteriores. El prólogo tiene como función en su obra contextualizar el relato con la finalidad de facilitar al lector una mayor comprensión del mismo. A pesar de esa vertiente histórica importante de que carecen las obras de las autoras anteriormente señaladas, Dieulafoy ofrece una descripción detallada e ilustrada con retratos de los monumentos, así como de figuras pintorescas para los habitantes allende los Pirineos, a saber, los guardias civiles (1901: 2): "En los andenes van y vienen los guardias civiles. Con su uniforme negro con galones y cuello rojo, su bicornio acharolado, sus pasamanerías blancas y su cinturón amarillo..." 9 . Se trata de un texto de mayor calidad literaria dirigido a lectores aficionados a los relatos de viaje o curiosos por conocer otros mundos, pero no para turistas tal como interpretamos hoy ese término. Bien es verdad que la autora diferencia a los viajantes de los turistas cuando dice que en la estación de Cerbère estos últimos se distinguen por llevar poco equipaje.

\section{La prensa: divulgadora de relatos de viaje}

El siglo xix es también el siglo de la prensa. Los relatos por fascículos se publican tanto en periódicos como en revistas especializadas - acabamos de señalarlo supra-. Una de las más importantes fue la de la editorial Hachette, Le Tour du monde, nouveau journal des voyages, creada en 1860 como un semanario que se vendía en las estaciones. El contenido de esos fascículos se publicaba más tarde en un número semestral. En 1895, el título cambió levemente convirtiéndose en la revista des voyages et des voyageurs. De este modo se introduce un elemento importante, el viajero. En nuestra opinión, el cambio de título no es inocente, amplía el abanico de lectores desde el que disfruta de la lectura por la simple curiosidad intelectual de conocer otras culturas que no visitará hasta aquel que pertenece al incipiente mundo del turismo. La Gran Guerra pondrá fin a la revista, como a tantas otras cosas; en 1914 dejó de publicarse ${ }^{10}$.

\subsection{La obra de Charles Davillier en la revista Le Tour du Monde}

En su primera etapa, entre 1862 y 1873, la revista publicó por entregas la obra del barón Jean Charles Davillier (1823-1883) Voyage en Espagne, cuya recopilación vio la luz en 1874 con el título L'Espagne. Las ilustraciones que acompañaban el texto, obra de Gustave Doré (18321883), uno de los ilustradores más reconocidos internacionalmente, dieron gran valor al texto.

9 La traducción es nuestra. Texto origen: "Sur les quais vont et viennent les guardias civiles. Avec leur uniforme noir relevé de parements et d'un col rouge, leur bicorne couvert d'une coiffe de toile cirée, leurs passementeries blanches et leur ceinturon jaune..." (Dieulafoy, 1901: 2). 
Davillier, buen conocedor de España y del idioma, no ahorra al lector los aspectos menos agradables del país. La descripción es cruda, sin la fantasía del romanticismo, apoyada por los dibujos de Doré, a quien considera imprescindible para mostrar la España real:

... tenía que acompañar a Doré en este viaje, se lo debía. Le había dicho más de cien veces que era el pintor perfecto para enseñarnos España; no la de las óperas cómicas y los keepsakes sino la España real con sus rústicos aragoneses, sus vigorosos catalanes, sus valencianos semidesnudos de piel curtida como bereberes, sus andaluces y sus trajes de cuero marrón, y sus orgullosos castellanos tan hábiles ellos para envolverse en andrajos inimaginables ${ }^{11}$. (Le Tour du monde 1862, 2e semestre: 290)

Del mismo modo que describe una iglesia o catedral, incluso la actividad comercial de la región que visita, el autor da cuenta meticulosamente de la situación social, con especial atención a la mendicidad, que considera casi una profesión aprendida de padres a hijos. Entre los pasajes del libro - para nosotros sorprendente - se encuentra un entierro y la ejecución por garrote de un reo, todo ello finamente ilustrado, lo que le confiere un mayor dramatismo. En su relato no podía faltar, naturalmente, la tauromaquia, cuyos dibujos dieron tanta fama a Gustave Doré. Sin embargo, no sería justo pensar que la obra se recrea en estas cuestiones luctuosas; Davillier solo hace un retrato realista de lo que ve con la mirada fría de un espectador distante.

\subsection{La obra de Valérie de Gasparin en el diario Las Provincias}

El caso siguiente es singular con respecto a los aquí presentados por cuanto una parte de la obra de Valérie de Gasparin -cuyo apellido de soltera era Boissier-A travers les Espagnes (1869) fue traducida y publicada en el diario valenciano Las Provincias y unos años más tarde, en 1875, su traducción completa vio la luz.

Valérie Boissier (1813-1894) fue una autora suiza

casada con el conde Agenor de Gasparin, agrónomo, político y ferviente protestante como ella misma [...]. Realizó varios viajes, que dejó plasmados en libros, como el Journal du voyage au Levant (1848), relato del viaje a Grecia, Turquía y Egipto, y dos volúmenes sobre sus viajes a España: A travers les Espagnes (1869) y Andalousie et Portugal (1886). (Lafarga, 2017: 252)

El estilo de la autora difiere de las anteriormente mencionadas por la mayor calidad literaria; su narración alterna la descripción del entorno - técnica propia de todo relato de viaje-con

11 La traducción es nuestra. Texto origen: “... je devais à Doré de l’accompagner dans ce voyage: cent fois je lui avais dit qu'il était le peintre qui devait nous faire connaître l'Espagne; non pas celle des opéras-comiques et des keepsakes, mais l'Espagne vraie avec ses rustiques Aragonais, ses vigoureux Catalans, ses Valenciens demi-nus et basanés comme des Khabyles, ses Andalous au costume de cuir fauve, et ses fiers Castillans, si habiles à se draper dans des haillons impossibles" (Le Tour du monde 1862, 2e semestre: 290). 
diálogos con los lugareños y entre los viajeros que la acompañan. Si bien la macroestructura es epistolar, Valérie de Gasparin no indica el receptor de la misiva ni la fecha, aunque Irene Atalaya (2016: 43) sitúa el viaje en 1865. En cuanto al contenido, este no muestra grandes diferencias con los autores románticos; la autora busca el exotismo representado por el Oriente, las huellas árabes en España. En definitiva, les Maures, como queda plasmado en un párrafo donde describe una supuesta batalla entre fuerzas musulmanas y españolas confesando que su corazón, esta vez, está del lado de los árabes a pesar de ser una ferviente católica: "Lo confieso, mi corazón está del lado de los Moros²” (1869: 8).

En 1866, nació en Valencia el diario Las Provincias - anteriormente La Opinión- de la mano del impresor José Doménech (1815-1879) y del periodista Teodoro Llorente (1836-1911), que lo dirigió hasta 1904. La obra de la condesa se incorporó al diario el mismo año de su publicación en 1869. Según Atalaya (2016: 44), “[e]l texto [traducido] se publicó en diez entregas, del 13 de agosto al 26 de septiembre, y recoge únicamente la parte dedicada a Valencia, sin duda por ser esta ciudad el lugar de publicación del diario". La autoría de la traducción del relato de la condesa de Gasparin se atribuye a Teodoro Llorente. El prólogo de la traducción del libro, publicado por Doménech (Valencia, 1875), está firmado por las iniciales T.LI., considerado por Atalaya (2016: 44) como "una de las figuras más importantes de la traducción en España segunda mitad del siglo XIX”. Al describir la figura de la autora, Llorente define al turista. En su opinión, Gasparin "[v]iajaba como hoy viaja la mayoría de las personas ilustradas, como simple turista, es decir como buscadora de sensaciones agradables, de novedades halagüeñas” (1875: 4). Se aprecia en el prólogo una crítica velada a ciertos relatos de viaje. Considera que el de Gasparin "no es un trabajo erudito", pues no se trata de un estudio serio.

La relación de su viage es una série de primeras impresiones, por lo general bastante exactas, y pintadas con vivo y brillante colorido. Incurre en algunos errores de detalle, porque en su rápido paseo por España vió mucho sin profundizar nada; pero el juicio general de forma suele ser acertado [...]. Déjase llevar, á veces, de su imaginación exuberante y prolonga las digresiones². (Gasparin, 1875: 4)

Se trata de elucubraciones que Llorente dice haber acortado. Observamos en este caso que la autora describe en su relato no solo lo que ve, sino sus impresiones, como dice Llorente. Lo cual no resulta sorprendente en una obra que no pretende ser científica.

\section{Gustave Clausse (1833-1914)}

Si bien hemos dado un trato preferente a las viajeras (apdo. 2) y a la función de la prensa en la divulgación de los relatos de viaje (apdo. 3), deseamos describir brevemente un tipo de viaje-

12 La traducción es nuestra. Texto origen: "Je vous l'avoue, mon coeur va du côté des Maures" (1869: 8).

13 Hemos mantenido la grafía original. 
ro-escritor diferente a los anteriormente mencionados. Se trata de viajeros con conocimientos concretos en una materia de los que cabría esperar un relato focalizado y especializado en su ámbito del saber. Sin embargo, no siempre fue así. El arquitecto Gustave Clausse publicó una obra titulada Espagne, Portugal. Notes historiques et artistiques sur les villes principales de la Péninsule Ibérique (Paris, 1889)14 en la que describe minuciosamente la estructura de las ciudades más importantes, así como sus monumentos, como era de esperar por el título. Podría pensarse asimismo que el autor se limita a los elementos arquitectónicos. Sin embargo, el libro se revela como una mezcla de relato de viajes y de historia del arte donde predomina, naturalmente, lo artístico y lo histórico.

La vertiente turística de la obra se distingue en la descripción exhaustiva del paisaje donde el autor detalla el trayecto entre ciudades con su visión particular, como en el párrafo siguiente, donde no ahorra adjetivos que destacan lo negativo del paisaje: "El tren que nos Ileva de Madrid a Toledo atraviesa unas tierras rojas, secas, peladas, deshabitadas, no se puede uno imaginar nada más feo. Se dice que las Ilanuras son excesivamente fértiles pero que una vez recogida la cosecha, no son nada pintorescas ${ }^{15}$ " (Clausse, 1889: 34).

En esta última palabra pintorescas, pensamos, se encuentra la clave de la descripción anterior. Clausse se identifica con el turista que viene con ideas preconcebidas, buscando una peculiaridad que no siempre encuentra. Ejemplo de ello es el entusiasmo con el que relata una corrida de toros, incluido el ambiente anterior a la misma. La descripción ocupa cinco páginas con un resumen que transcribimos a continuación:

Resumiendo, es un espectáculo espléndido; cierto es que ver a los caballos reventados es sin duda repugnante, pero no hay que fijarse en ello sino concentrarse en la lucha del hombre contra el toro. Ahí es donde se aprecia un magnífico enfrentamiento. Las banderillas se ponen con tal habilidad y temeridad que la percepción de peligro desaparece; y con la gracia y la agilidad de los banderilleros se eliminaría totalmente si el toro no se encargara de recordarnos de vez en cuando, por una buena embestida, que la vida del hombre siempre está en peligro en ese juego ${ }^{16}$. (Clausse, 1889: 20)

14 No hemos encontrado traducción alguna de la obra.

15 La traducción es nuestra. Texto origen: "Le chemin de fer qui conduit de Madrid à Tolède traverse une champagne rousse desséchée, râpée, inhabitée, tout ce qu’on peut imaginer de plus laid. Les plaines sont, dit-on, excessivement fértiles, mais, la récolte une fois faite, elles manquent complétement de pittoresque" (Clausse, 1889: 34).

16 La traducción es nuestra. Texto origen: "En résumé, c'est un splendide spectacle; l'éventrement des cheveaux est certainement répugnant, mais il faut en tenir peu de compte et concentrer toute son attention sur la lutte entre l'homme et le taureau; il y a là une magnifique passe d'armes. La pose des banderilleros se fait avec une adresse et une témérité telles que le danger semble disparaître; la grâce et l'agilité des banderilleros le ferait tout à fait oublier, si le taureau ne se chargeait quelques fois de rappeler, par quelque bonne brutalité, que la vie de l'homme est, à ce jeu-là, toujours en danger" (Clausse, 1889: 20). 
Constatamos, pues, en las dos citas anteriores que Clausse no se sustrae a la moda del momento e integra en su obra una parte turística en el sentido pleno de la palabra, así como tópica en su mirada hacia la mujer, especialmente la sevillana: "La reputación de la belleza de las mujeres de Sevilla está justificada, pero casi todas se parecen: mismo porte altivo, mismos cabellos negros y brillantes, mismos ojos rasgados de pestañas morenas. Para apreciarlo, hay que ir a la fábrica de tabaco ${ }^{17}[\ldots .$.$] " (Clausse, 1889: 114).$

En cuanto a la parte de la obra considerada no turística, es decir, monumental, cultural e histórica - a nuestro entender - se desprende igualmente un juicio crítico, esta vez propio de su formación como arquitecto e historiador del arte. Estimamos especialmente relevante la descripción que lleva a cabo de la obra de Velázquez y de los grandes pintores cuyos cuadros se encuentran en el Museo del Prado, que el autor llama simplemente musée: "El museo de Madrid puede competir con las más dignas galerías de Europa, tanto por la cantidad como por la calidad de los cuadros de maestros de todas las escuelas; pero en ningún sitio en el mundo la pintura española está representada por un número tan considerable de obras de arte $^{18 ”}$ (Clausse, 1889: 23).

Para el lector de finales del XIX, el texto de Gustave Clausse, a pesar de su título, se revela como una sucesión de datos de distinta índole no solo compuesta de notas artísticas e históricas.

\section{Lucien Boileau, Alphonse Roswag (1833-1900): autores de guías turísticas}

Los dos títulos que hemos reservado para la última parte de este estudio son el de Lucien Boileau ${ }^{19}$, Voyage pratique d'un touriste en Espagne (Paris, 1889), y el Nouveau guide du tourisme en Espagne et Portugal. Itinéraire artistique, de Alphonse Roswag (Madrid, 1879). Alphonse Roswag fue un fotógrafo francés casado con la hija de Jean Laurent, fotógrafo de la Corte y fundador de una empresa fotográfica cuya actividad era la publicación de todo tipo de imágenes (retratos, monumentos, ciudades...). En 1881, Roswag se hizo cargo de la compañía y se volcó hacia las guías turísticas, además de ampliar los catálogos fotográficos (V. Laurent et Cie, en línea).

17 La traducción es nuestra. Texto origen: “Les femmes de Séville justifient leur réputation de beauté, mais elles se ressemblent presque toutes: même allure fringante, même cheveux noirs et lustrés, mêmes yeux largement fendus, frangés de cils bruns. Pour en juger, il faut visiter la célèbre manufacture de tabac [...]" (Clausse, 1889: 114).

18 La traducción es nuestra. Texto origen: "Le musée de Madrid peut lutter avec les plus remarquables galeries d'Europe, tant pour la quantité que pour la qualité des tableaux des maîtres de toutes les écoles; mais nulle part au monde la peinture espagnole n'est représentée par un aussi grand nombre de chef-d'oeuvres" (Clausse, 1889: 23).

19 No hemos encontrado datos biográficos de este autor. 
En el caso de estos dos autores no ha lugar a duda, se trata de guías turísticas cuya finalidad es aconsejar al turista en su viaje por la península ofreciendo información práctica según Boileau y ordenada según Roswag. La ruta turística que proponen está directamente relacionada con la red ferroviaria, pues los destinos son las ciudades más importantes por donde pasa el ferrocarril; otra de las razones tenida en cuenta es la comodidad que proporciona al viajero el nuevo medio de locomoción.

En las dos guías, los autores coinciden en su deseo de distanciarse de los relatos de viajes fantasiosos o poco precisos. Por un lado, Boileau confiesa su intención de alejarse de los prejuicios:

Escribir sin apriorismos, guardándose tanto del entusiasmo como de la denigración y describir con fidelidad lo que he visto y que es accesible a cualquier viajero. He querido seguir el itinerario del gran viaje circular, gracias al cual el viaje por España es hoy día casi tan fácil como cualquier otro. Así, al escribir fundamentalmente para el turismo [...], he podido dar a esta obra el epíteto de práctica mostrando con ello la finalidad de la misma ${ }^{20}$. (1889: 2)

Por otro, Roswag manifiesta limitarse a informar sobre el lado artístico y pintoresco de los viajes, así como histórico, dejando de lado la información sobre los productos del lugar y sus administraciones: "Sin embargo, hemos dado preferencia a todo lo artístico y pintoresco de los viajes a través de la Península, sin descuidar por ello la descripción minuciosa de lo histó$\operatorname{rico}^{21 ”}(1879$ : Iv).

La guía de Roswag está editada cuidadosamente con el fin de facilitar la lectura; va acompañada de un mapa de la red ferroviaria de la península y un índice onomástico de las ciudades. En ella, la historia ocupa un lugar primordial en los artículos que recogen lo esencial de cada ciudad. Hemos elegido una ciudad pequeña, Sagunto, pero con un pasado histórico importante como ejemplo.

Murviedro: es la antigua Sagunto. Largas líneas de fortificaciones coronan las alturas: al pie de las ruinas de esta Antigua y gloriosa ciudadela, se extiende la ciudad moderna de Murviedro (muri veteres o viejos muros), que sale de sus viejas murallas para extenderse cómodamente por la llanura. Fundada por los griegos al borde del mar, ha visto secarse lentamente su puerto como con-

20 La traducción es nuestra. Texto origen: "Écrire sans parti pris, en se tenant aussi loin de l'enthousiasme que du dénigrement et de dépeindre avec fidélité ce que j'ai vu et qui est accessible à tout voyageur. J'ai voulu suivre l'itinéraire du grand voyage circulaire, grâce auquel le voyage en Espagne est devenu aujourd'hui presque aussi facile que tout autre. C'est ainsi qu'en écrivant spécialement en vue du tourisme [...] j'ai pu donner au texte de cet ouvrage l'épithète de pratique qui en démontre suffisamment le but" (1889: 2).

21 La traducción es nuestra. Texto origen: "Nous nous sommes attachés par contre et de préférence au côté artistique et pittoresque des voyages à travers la Péninsule, sans négliger de développer soigneusement le côté historique" (1879: Iv). 
secuencia de la retirada del mar situado actualmente a más de una legua de distancia. [...] Unos atribuyen su fundación a los Escipiones y otros al emperador Claudius Germanicus. Estas ruinas tan interesantes todavía estaban intactas a principios de siglo...22 (Roswag, 1879: 170-171)

\section{Conclusiones}

Al iniciar este artículo, nuestro deseo era definir con la mayor claridad posible la figura del viajero y del turista, dónde terminaba uno y empezaba el otro. Este estudio ha revelado que, en el espacio de tiempo considerado, ya se hacía la diferencia entre viajeros y turistas. Para Joséphine de Brinkmann (1852), el turista es aquel que viaja con la mente abierta y sin prejuicios. Juliette de Robersart (1879) no muestra claramente su opinión sobre el turista. En cuanto a Jane Dieulafoy (1901), lo único que distingue al turista, en su opinión, es el poco equipaje que lleva.

Coincidiendo en el tiempo con estas publicaciones, la prensa se hace eco asimismo de relatos sobre viajes; esto amplía su gama editorial y, por lo tanto, su negocio, lo que da una idea del interés del lector del momento y probablemente futuro turista. Hemos observado la influencia de este tipo de relato en el arquitecto Gustave Clausse, cuya obra combina la descripción superficial propia del espectador, léase, turista, y la erudita en lo artístico. En definitiva, solo los textos de Boileau y Roswag van dirigidos a los turistas, tal como entendemos ese término actualmente: la persona que viaje por placer con un recorrido programado en un tiempo limitado.

Esta reflexión nos Ileva a la conclusión de que, en el último tercio del siglo xIx, con la implantación del ferrocarril y por ende de las comodidades, el viajero que visitaba España se convertía en turista.

\section{Bibliografía citada}

AtalAya, Irene, 2016: "Literatura de viajes y su traducción: el caso de Paseo por España (1875) de Valérie de Gasparin”, Estudios Románicos 25, 41-52.

22 La traducción es nuestra. Texto origen: "Murviedro: c'est l'ancienne Sagonte. De longues lignes de fortifications couronnent les hauteurs: c'est au pied des ruines de cette Antique et glorieuse cité, que s'étend la ville moderne de Murviedro (muri veteres ou vieux murs), sortie de ses vieilles murailles pour aller s'étaler plus à l'aise à la plaine. Fondée par les Grecs, sur le bord de la mer, elle a vu lentement son port rester à sec, par suite du retrait de la mer qui est actuellement à plus d'une lieue. [...] Sa fondation est attribuée par les uns aux Scipions et par les autres à l'empereur Claudius Germanicus. Ces ruines si intéressantes étaient encore intactes au commencement du siècle..." (Roswag, 1879: 170-171). 
BoIleAu, Lucien, 1889: Voyage pratique d'un touriste en Espagne, ouvrage illustré, París: E. Dentu éditeur.

Brinkmann, Joséphine de, 1852: Promenades en Espagne pendant les années 1849 et 1850, par Mme de Brinckmann, née Dupont-Delporte, París: chez Franck libraire-éditeur.

Brinkmann, Joséphine de, 2001: Paseos por España (1849-1850), edición y traducción de María Luisa Burguera, Madrid: Cátedra.

Clausse, Gustave, 1889: Espagne, Portugal. Notes historiques et artistiques sur les villes principales de la Péninsule Ibérique, París: Librairie de l'art [https://gallica.bnf.fr/ark:/12148/bpt6k5695268r.textelmage, fecha de consulta: 25 de julio de 2020].

DavilLIeR, Charles, 1874: L'Espagne par le baron Ch. Davillier illustrée de 309 gravures dessinées sur bois par Gustave Doré, París: Hachette.

Dieulafor, Jane, 1901: Aragon et Valence, París: Hachette.

Dieulafor, Jane, 1908: Castilla et Andalousie, París: Hachette.

El Correo de Andalucía. "Hospital de la Caridad: obnubilados por la historia" [https://elcorreoweb.es/sevilla/hospital-de-la-caridad-obnubilados-por-la-historia-KG4282048, fecha de consulta: 22 de agosto de 2020].

Gasparin, Valérie de, 1869: À travers les Espagnes. Catalogne, Valence, Alicante, Murcie et Castille par l'auteur des Horizons prochains, Paris: Michel Lévy Frères.

Gasparin, Valérie de, 1875: Paseo por España. Relación de un viaje a Cataluña, Valencia, Alicante, Murcia y Castilla por la condesa de Gasparin, Valencia: Imprenta de D. José Doménech

Lafarga Francisco, 2017: "Luz y tinieblas en el relato de viajeras francesas a España en la segunda mitad del siglo XIX" en María Loreto Cantón Rodriguez, Isabel Esther González Alarcón, Covadonga Grijalba Castaños, Yolanda B. Jover Silvestre (eds.): Metáforas de la luz, Almería: Universidad de Almería.

RoBERSART, Juliette de, 1879: Lettres d'Espagne par la comtesse J. de Robersart, Nouvelle édition considérablement augmentée, París: Watelier.

Roswag, Alphonse, 1879: Nouveau guide du tourisme en Espagne et Portugal. Itinéraire artistique, Madrid: J. Laurent et Cie.

J. LaURent et Cie: "Salamanca en el ayer" [https://www.salamancaenelayer.com/2015/01/j-laurent-et-cie.html, fecha de consulta: 22 de agosto de 2020]. 
Shafa, Shojaeddin, 2000: De Persia a la España musulmana: la historia recuperada [traducido por Ma Ángeles Gallego García], Huelva: Universidad de Huelva.

TorRe Giménez, Estrella de la, 2006: "Nuestro patrimonio cultural analizado por una viajera del siglo XIX: Juliette de Robersart” en Manuel Bruña Cuevas, María de Gracia Caballos Bejano, Inmaculada Illanes Ortega, Carmen Ramírez Gómez, Anna Raventós Barangé (eds.): La cultura del otro: español en Francia, francés en España, Sevilla, 710-720.

Torre Giménez, Estrella de la, 2007: Cartas de España Condesa Juliette de Robersart. Un excitante viaje a la España del siglo xix a través de los ojos de la condesa, Badajoz: Abecedario. 